\title{
烟草非特异性脂质转移蛋白基因家族的鉴定与分析
}

\author{
李 鹏 ${ }^{1}$ 刘 彻 ${ }^{1}$ 宋 皓 ${ }^{1} \quad$ 姚盼盼 $^{1} \quad$ 苏沛霖 $^{1}$ 魏跃伟 ${ }^{1}$ 杨永霞 ${ }^{1}$ * $^{*}$ \\ 李青常 ${ }^{*}$ *
}

1 河南农业大学烟草学院, 河南郑州 $450002 ;{ }^{2}$ 中国烟草总公司郑州烟草研究院, 河南郑州 450001

摘 要: 植物非特异性脂质转移蛋白 (non-specific lipid transfer proteins, nsLTPs)可以在体外转移脂质, 调节植物的生 长发育以及对环境非生物和生物胁迫作出反应等。本研究从烟草栽培品种 K326 (Nicotiana tabacum L.) 基因组中鉴定 出 74 个 nsLTPs 基因，对其系统发育关系、基因结构、保守基序、染色体定位、基因重复、启动子顺式作用元件、 $3 \mathrm{D}$ 结构和激素与非生物胁迫处理下的表达模式进行了分析。结果表明, 根据 8 个半胱氨酸之间的间隔和序列相似性 将其分为 I、II、III、IV、V、VII、VIII 和 XIII 八种类型, 相同类型的 NtLTPs 具有相似的内含子-外显子基因结构和 保守基序模式, motif 2 和 motif 3 是 NtLTPs 基因家族的特征基序。在进化过程中, 片段重复是 NtLTPs 基因家族扩展 的主要原因, 干旱处理后的 RNA-seq 分析发现, 在进化过程中, 不同基因重复事件发生后功能分化模式存在差异。启 动子分析表明, 它们含有多种光反应、激素和非生物胁迫响应顺式作用元件。进一步采用 qRT-PCR 分析发现, NtLTPs 家族基因在烟草植株的不同组织和器官中具有不同的表达模式, 可以响应干旱、盐等非生物胁迫以及 IAA、GA、SA 等激素处理。研究结果为深入分析 NtLTPs 家族基因的功能提供了理论参考, 并为进一步的分子育种提供了理论基础。 关键词：烟草; nsLTPs; 基因家族; 生物信息学; 基因表达

\section{Identification and analysis of non-specific lipid transfer protein family in tobacco}

\author{
LI Peng ${ }^{1}$, LIU Che ${ }^{1}$, SONG Hao ${ }^{1}$, YAO Pan-Pan ${ }^{1}$, SU Pei-Lin ${ }^{1}$, WEI Yao-Wei ${ }^{1}$, YANG Yong-Xia ${ }^{1, *}$, and LI \\ Qing-Chang ${ }^{2, *}$ \\ ${ }^{1}$ Tobacco College, Henan Agricultural University, Zhengzhou 450002, Henan, China; ${ }^{2}$ Zhengzhou Tobacco Research Institute of CNTC, Zhengzhou \\ 450001, Henan, China
}

\begin{abstract}
Plant non-specific lipid transfer proteins (nsLTPs) can transfer lipids in vitro, regulate plant growth and development, and respond to environmental abiotic and biotic stresses. In this study, 74 nsLTPs genes were identified from the genome of Nicotiana tabacum variety K326, and we analyzed multiple characteristics of these genes, including phylogeny, gene structures, conserved motifs, protein domains, chromosome locations, cis-elements in the promoter sequences, 3D structure, and the expression patterns under different hormones and abiotic stresses. The results revealed that nsLTPs in tobacco could be divided into eight types, including type I, II, III, IV, V, VII, VIII, and XIII, according to the interval and sequence similarity between the eight cysteines. The same types of NtLTPS had similar intron-exon patterns and conserved motifs, motif 2 and motif 3 were the characteristic motifs of NtLTPS family. In the process of evolution, fragment duplication dominated the expansion of the NtLTPs family. RNA-seq analysis after drought treatment revealed that the functional differentiation patterns of repeat gene pairs were diverse during evolution period. Promoter analysis showed that they contained a variety of cis-acting elements in response to light response, hormones, and abiotic stress. Furthermore, qRT-PCR demonstrated that NtLTPs family genes had different expression
\end{abstract}

本研究由河南省科技攻关计划(农业领域)项目 (182102110315，192102110002，192102110121), 河南省大学生创新创业训练计划项目 (S202010466013)和河南农业大学本科实验室开放创新项目(KF1908)资助。

This study was supported by the Henan Province Science and Technology Research Plan (Agricultural Field) Project (182102110315, 192102110002, 192102110121), the Henan University Student Innovation and Entrepreneurship Training Program (S202010466013), and the Open Innovation Project of Undergraduate Laboratory of Henan Agricultural University (KF1908).

*通信作者(Corresponding authors): 杨永霞, E-mail: yyx624@126.com; 李青常, E-mail: ctsrc@126.com

第一作者联系方式: E-mail: 1peng1995@126.com

Received (收稿日期): 2020-11-05; Accepted (接受日期): 2021-04-26; Published online (网络出版日期): 2021-05-13.

URL: https://kns.cnki.net/kcms/detail/11.1809.S.20210513.1258.002.html 
patterns in different tissues and organs of tobacco plants, which could respond to abiotic stresses such as drought, salt, and hormone treatments (IAA, GA, and SA etc.). These results provide a theoretical reference for the in-depth analysis of the functions of NtLTPs family genes and molecular breeding.

Keywords: tobacco; nsLTPs; gene family; bioinformatics; gene expression

非特异性脂质转移蛋白(nsLTPs)是一类小的、碱 性蛋白质, 分子量约为 $6.5 \mathrm{kD}$ 至 $10.5 \mathrm{kD}$, 在高等植 物中含量丰富, 占总可溶性蛋白的 $4 \%$ 左右 ${ }^{[1]}$ 。 NsLTPs 家族的特征是它们都有一个包含 8 个半胱氨 酸的基序(Eight Cysteine Motif, ECM), 其一般形式 为 C-Xn-C-Xn-CC-Xn-CXC-Xn-C-Xn-C (“X”代表任 何氨基酸, “ $n$ ”表示氨基酸残基数), 三级结构可以形 成带有 4 个或 5 个 $\alpha$-螺旋的疏水腔, 在体外可以结 合或转移脂肪酸、脂肪酰基-CoA、磷脂、糖脂和角 质单体等疏水分子 ${ }^{[2-3]}$ 。

NsLTPs 是由多个基因组成的复杂家族, 自发现 至今, 其分类方法不断完善。目前 nsLTPs 的分类主 要有 3 种, 一是根据 nsLTPs 的分子量大小, 将 nsLTPs 分为 2 种类型: nsLTPI (分子量大约为 $9 \mathrm{kD}$ ) 和 nsLTP II (分子量大约为 $7 \mathrm{kD})^{[4]}$ 。二是 Boutrot 等 ${ }^{[5]}$ 在对水稻、小麦和拟南芥的全基因组分析中, 根 据序列相似性以及 8 个半胱氨酸之间的氨基酸残基 数量将 nsLTPs 分为 9 种类型(I、II、III、IV、V、 VI、VII、VIII、IX 型)。基于这个分类方法, 而后在 其他物种中略有修改, Liu 等 ${ }^{[6]}$ 将 135 个茄科 nsLTPs 基因分为 5 种类型( $\mathrm{I} 、 \mathrm{II} 、 \mathrm{IV} 、 \mathrm{IX}$ 和 $\mathrm{X}$ ), 额外增加 一个 X 型, I 型被划分为了 Ia、Ib、Ic、Id 4 个亚型; D'Agostino 等 ${ }^{[7]}$ 将番茄中 64 个 nsLTPs 基因分为 6 个类型(I、II、III、IV、X 和 XI 型), 额外增加了一 个 $\mathrm{XI}$ 型。 $\mathrm{Li}$ 等 ${ }^{[8]}$ 将马铃薯中 83 个 nsLTPs 基因分为 I、II、IV、V、VII、VIII、XII 和 XIII 8 种类型, 增 加 XII 和 XIII 2 种类型。三是 Edstam 等 ${ }^{[9]}$ 在对苔藓、 蕨类等隐花植物的 nsLTPs 分类时, 根据 nsLTPS 内 含子的位置、编码蛋白中潜在的糖基磷脂酰肌醇修 饰位点和半胱氨酸之间的间隔, 将 nSLTPS 划分为 10 种类型 (I、II、C、D、E、F、G、H、J 和 $\mathrm{K}$ )。 与此类似的分类方法也被应用于许多物种中, 在对 330 个小麦、63 个玉米和 70 个大麦 nsLTPs 基因的 分类中, 根据此方法划分为 I、II、C、D、G 5 种类 型 ${ }^{[10-12]}$ 。

NsLTPs 涉及参与植物许多生理生化过程, 具有 多种生物学功能 ${ }^{[13]}$, 包括植物的有性生殖、信号传 导、植物角质层蜡质的生物合成、花粉和纤维的伸 长、细胞凋亡和果实成熟等过程 ${ }^{[14-20]}$ 。NsLTPs 参与
生物与非生物胁迫应激反应。nsLTPs 可以作为一种 天然的抗菌肽物质, 参与 SAR 信号转导过程, 与植 物系统获得性抗性有关, 并在细胞程序性死亡、植 物抗逆和抗病过程中起着重要作用 ${ }^{[21]}$ 。研究发现, 拟南芥 AtLTP3 参与对干旱胁迫的响应 ${ }^{[22]}$ 。过表达拟 南芥 AtLTP4.4 基因可使谷胱甘肽水平升高, 增强抗 氧化防御能力, 提高拟南芥对单端狍菌毒素的抗 性 ${ }^{[23]}$ 。水稻中过量表达 LTP1 和 LTP2 基因可提高对 真菌和细菌病害的抗性 ${ }^{[24]}$ 。黄瓜CSLTP_2 基因在对 根结线虫感染的防御中起重要作用 ${ }^{[25]}$ 。过表达小麦 TaLTP5 基因可以提高小麦对禾旋狍腔菌和禾谷镰 孢菌的抵抗能力 ${ }^{[26]}$ 。除此之外, nsLTPs 还是植物性 食物和花粉中的过敏原, 引起过敏反应 ${ }^{[27-28]}$ 。

虽然在一些物种中对 nsLTPs 基因家族已有相关 报道, 但烟草作为一种重要的模式和经济作物, 还 没有相关报道, 仅对个别基因家族成员的功能进行 研究。研究发现, 烟草 NtLTP1 在叶片表面长柄腺毛 中大量表达, 过表达 NtLTP1 可使叶片脂质分泌增多, 显著提高对蚜虫的抗性 ${ }^{[29]}$ 。过表达 NtLTP4 基因可 以调控 2 个 $\mathrm{Na}^{+}$转运体 NHX1 和 HKT1, 改变烟草体 内 $\mathrm{Na}^{+}$的稳态, 进而减弱 $\mathrm{Na}^{+}$对细胞的毒害作用, 增 强烟草对盐胁迫的耐受性 ${ }^{[30]}$ 。鉴于此, 本研究拟从 烟草中鉴定 nsLTPs 基因家族, 并对其进行详细的生 物信息学分析, 研究其在不同胁迫下的表达模式, 为进一步深入研究 NtLTPs 的功能提供理论基础。

\section{1 材料与方法}

\section{1 烟草 nsLTPs 家族成员的搜索和鉴定}

从 PFAM 数据库中下载 nsLTPs 蛋白保守的结构 域 PF00234 和 PF14368, 并以此为查询序列, 采用 HMMER 软件, 以國值 $E<1 \mathrm{e}^{-5}$ 作为默认参数, 在茄 科基因组网站(https://solgenomics.net/)进行搜索并 下载烟草栽培品种 K326 nsLTPs 基因组序列和其上 游 $2000 \mathrm{bp}$ 的启动子序列, 进一步在 PFAM 和 SMART (http://smart.embl-heidelberg.de/)数据库进 行确认, 并使用 NCBI 保守结构域 CDD 数据库 (https://www.ncbi.nlm.nih.gov/cdd)分析 nsLTPs 蛋白 的保守结构域, 剔除含不完整 ECM 基序、其他结构 域及注释不完整的序列。 


\section{2 烟草 nsLTPs 的序列分析与系统发育树构建}

使用在线工具 SignaIP 5.0 (http://www.cbs.dtu. $\mathrm{dk} /$ services/SignalP/预测 nsLTPs 蛋白的信号肽序列; ExPASy-ProtParam (https://web.expasy.org/protparam/) 计算全长蛋白的分子量和等电点。使用 MEGA 6.0 软件的 Muscle 比对全长蛋白, 邻接法(neighborjoining, NJ)构建系统发育树, 参数设置为具有 1000 次重复的 JTT 模型。

\section{3 烟草 nsLTPs 的基因结构和 motif 分析}

使用在线网站 GSDS 2.0 (http://gsds.cbi.pku. edu.cn/)绘制 NtLTPS 基因的内含子-外显子结构图; 在线网站 MEME (http://meme-suite.orgGSDS)预测烟 草 nsLTPs 的保守基序，参数设定保守基序数量为 10 。

\section{4 烟草 nsLTPs 的染色体定位与共线性分析}

在线网站 MapGene2 Chrome V2 (http://mg2c. iask.in/mg2c_v2.0/) 用来分析可以定位到烟草品种 K326 染色体上的基因。使用 TBtools 软件的 Circos 功能可视化重复基因对之间的关系。同样地，重复基 因对之间的 $\mathrm{Ka} / \mathrm{Ks}$ 值使用 TBtools 软件进行计算 ${ }^{[31]}$ 。

\section{5 烟草 nsLTPs 蛋白的 3D 结构分析}

使用 SWISS-MODEL 在线网站预测 nsLTPs 蛋 白的 3D 结构, 然后用 PyMoL 软件进行可视化。

\section{6 烟草 nsLTPs 顺式作用元件分析}

使用 Plantcare (http://bioinformatics.psb.ugent. be/webtools/plantcare/html/) 在线网站预测和分析 $N t L T P s$ 基因上游 $2000 \mathrm{bp}$ 启动子的顺式作用元件 ${ }^{[32]}$ 。

\section{7 干旱处理下的 RNA-seq 分析}

从 NCBI 的 SRA 数据库中下载六周左右的烟草 品种 K326 幼苗在干旱处理下的 RNA-seq 数据 (https://www.ncbi.nlm.nih.gov/bioproject/PRJNA6916 42), 并使用 TBtools 软件的 FastQC 和 Trimmmonatic 功能对测序数据进行质量控制，去除接头污染和低 质量碱基, 然后将其定位到烟草品种 K326 的参考 基因组上，最终获得过滤后的烟草品种 K326 在干 旱处理下 $n s L T P S$ 基因的表达量用于后续分析。基因 表达量的计算使用 FKPM 法(每百万 fragments 中来 自某一蛋白编码基因每千碱基长度的 fragments 数 目), 使用 TBtools 软件的 Different Gene Expression Analysis (DESeq2)插件作差异基因表达分析, 将 FDR (adjusted $P$-value)小于 0.05 且表达差异大于 2 的基因视为差异表达基因，最后使用 TBtool 软件的 HeatMap 功能对 nsLTPs 基因的 FPKM 值进行 $\log _{2}$ 标准化后绘制差异基因表达量热图。

\section{8 植物材料与处理}

烟草品种 $\mathrm{K} 326$ 采用漂浮育苗, 并在恒定的生 长条件 $\left(28^{\circ} \mathrm{C}, 16 \mathrm{~h}\right.$ 光照, $8 \mathrm{~h}$ 黑暗, $600 \sim 800 \mu \mathrm{mol}$ 光子 $\mathrm{m}^{-2} \mathrm{~s}^{-1}$ ，相对湿度为 $60 \sim 70 \%, \mathrm{CO}_{2}$ 浓度为 $400 \sim 450$ $\mu \mathrm{mol} \mathrm{mol}{ }^{-1}$ )下进行培养, 直到生长至 4 片真叶(生根 期)时进行处理, 分别采用 $100 \mu \mathrm{mol} \mathrm{L} \mathrm{L}^{-1}$ 的脱落酸 (abscisic acid, ABA)、茉莉酸甲酯(methyl jasmonate, MeJA)、赤霉素(gibberellins, GA)、生长素(auxin, IAA) 和 $2 \mathrm{mmol} \mathrm{L}^{-1}$ 的水杨酸(salicylic acid, SA)喷酒幼苗, 将幼苗放放置于边长为 $40 \mathrm{~cm}$ 的方形托盘中, 每种 激素喷施 $60 \mathrm{~mL}$ 。另外, 于 $37^{\circ} \mathrm{C}$ 下处理幼苗 $48 \mathrm{~h}$ 模 拟高温逆境。干旱和盐胁迫处理是将幼苗分别在浓 度为 $200 \mathrm{mmol} \mathrm{L}^{-1}$ 甘露醇和 $200 \mathrm{mmol} \mathrm{L}^{-1} \mathrm{NaCl}$ 的溶 液中培养 $48 \mathrm{~h}$ 。以上处理, 分别在 $0 、 1 、 3 、 6 、 9 、$ 12、24 和 $48 \mathrm{~h}$ 采集从上往下数第 2 片叶的叶片组织 样本，每个时刻 3 个重复。组织表达特异性分析是 在开花期收集烟草植株不同组织和器官 (根、茎、上 部叶、中部叶、下部叶和花), 所有采集的样品均在 液氮中迅速冷冻, $-80^{\circ} \mathrm{C}$ 保存, 用于分析 $N t L T P s$ 基因 的表达模式。每个样品进行 3 个生物学重复和 3 个 技术重复。

\section{9 实时苂光定量 PCR}

使用植物总 RNA 分离试剂盒提取每个样品的 总 RNA。HiScript II Reverse Transcriptase (NO.R20101/02)试剂盒(南京诺唯赞生物科技股份有限公司) 进行反转录。利用 Primer 5.0 软件设计实时苂光定 量(Quantitative Real-time, qRT) PCR 引物, 以 $L 25$ 作为内参基因(表 1)。qRT-PCR 反应体系包含 $1 \mu \mathrm{L}$ cDNA、 $5 \mu \mathrm{L}$ AceQ Universal SYBR qPCR Master Mix (Vazyme, 中国)、正/反向引物各 $0.5 \mu \mathrm{L}$ 和 $3 \mu \mathrm{L}$ $\mathrm{ddH}_{2} \mathrm{O}$ 。在实时苂光定量 PCR 仪(Eppendorf，德国) 上进行 $\mathrm{PCR}$ 反应, 程序为 $95^{\circ} \mathrm{C}$ 预变性 $10 \mathrm{~min}$; $95^{\circ} \mathrm{C}$ 变性 $10 \mathrm{~s}, 60^{\circ} \mathrm{C}$ 退火 $30 \mathrm{~s}, 35$ 个循环。采用 $2^{-\Delta \Delta \mathrm{CT}}$ 算法计算基因的相对表达量。

表 1 引物列表

Table 1 Primers used in this study

\begin{tabular}{ll}
\hline \multicolumn{1}{c}{ 引物名称 Primer name } & \multicolumn{1}{c}{ 引物序列 Primer sequence (5'-3') } \\
\hline L25-F & CCCCTCACCACAGAGTCTGC \\
L25-R & AAGGGTGTTGTTGTCCTCAATCTT \\
Nitab4.5_0000125g0010-F & CGGATCGCCGGAGTGTTTGC \\
Nitab4.5_0000125g0010-R & GCCACATTTGCCAGGGAGGG \\
Nitab4.5_0004362g0040-F & AAGCCGATTTGCGTTGTATG \\
Nitab4.5_0004362g0040-R & CTTAGGCAGTTTCATAGCAG \\
\hline
\end{tabular}




\section{2 结果与分析}

\section{1 烟草 nsLTPs 基因家族成员的鉴定}

从烟草品种 $\mathrm{K} 326$ 基因组中搜索得到 122 条 NtLTPS 序列。使用 NCBI 的 Blastp 和 CD-Search 功 能对 NtLTPS 进行分析, 删除了 47 条不包含完整 ECM 基序、含有其他结构域及注释不完整的序列和 1 条富含脯氨酸的序列, 剩余 74 条 N $t L T P S$ 序列用于 以下分析。

\section{2 烟草 nsLTPs 基因家族成员的序列分析与分类}

根据 Boutrot 等 ${ }^{[5]}$ 的分类方法, 基于 ECM 的序 列相似性以及 8 个半胱氨酸之间的间隔, 将烟草品 种 K326 的 nsLTPs 序列划分为 8 种类型: I、II、III、 IV、V、VII、VIII、XIII，没有 VI 和 IX 型，并依据
同为茄科的马铃薯中的分类方法, 新增了一个 XIII 型 ${ }^{[23]}$ 。对每种类型 NtLTPs 的 8 个半胱氨酸之 间的间隔进行统计(表 2)。I 型中的 NtLTPs 数量最多, 有 38 条, 其次为 IV 型, 有 10 条, III 型和 V 型的数 量最少, 各有 1 条。VII 型和 VIII 的主要区别在于第 1 个半胱氨酸和第 2 个半胱氨酸之间的数量, 而 XIII 型的不同之处在于第 6 个和第 7 个半胱氨酸之间的 氨基酸残基数量。

信号朋预测结果显示, 有 67 条 NtLTPs 序列含 有 $\mathrm{N}$-末端信号肽, 占总序列的 $90.5 \%$, 信号肽长度 约为 16 31 个氨基酸。通过计算 NtLTPs 全长蛋白的 分子量和等电点发现, 烟草 nsLTPs 蛋白的分子量相 对较小, 大部分为 $10 \sim 15 \mathrm{kD}$, 而大多数 nsLTPs 蛋白 的等电点在 8 10 间(图 1)。

表 2 烟草 nsLTPs 八个半胱氨酸基序(ECM)的多样性

Table 2 Diversity of eight-cysteine motifs (ECM) of nsLTPs in tobacco

\begin{tabular}{|c|c|c|c|c|c|c|c|c|c|c|c|c|}
\hline $\begin{array}{l}\text { 类型 } \\
\text { Type }\end{array}$ & $\begin{array}{c}\text { 数量 } \\
\text { Number of members }\end{array}$ & & & & & & $\mathrm{ECM}$ & & & & & \\
\hline I & 38 & $\mathrm{C}$ & $\mathrm{X}_{9,24}$ & $\mathrm{C}$ & $X_{12-16}$ & $\mathrm{CC}$ & $\mathrm{X}_{19,20,22}$ & $\mathrm{CXC}$ & $X_{21-23}$ & $\mathrm{C}$ & $X_{10-15,25}$ & $\mathrm{C}$ \\
\hline II & 6 & $\mathrm{C}$ & $X_{7}$ & $\mathrm{C}$ & $\mathrm{X}_{13}$ & $\mathrm{CC}$ & $\mathrm{X}_{8}$ & $\mathrm{CXC}$ & $X_{23}$ & $\mathrm{C}$ & $X_{6,10}$ & $\mathrm{C}$ \\
\hline III & 1 & $\mathrm{C}$ & $\mathrm{X}_{9}$ & $\mathrm{C}$ & $\mathrm{X}_{14}$ & $\mathrm{CC}$ & $\mathrm{X}_{9}$ & $\mathrm{CXC}$ & $X_{12}$ & $\mathrm{C}$ & $\mathrm{X}_{6}$ & $\mathrm{C}$ \\
\hline IV & 10 & $\mathrm{C}$ & $\mathrm{X}_{9,10}$ & $\mathrm{C}$ & $\mathrm{X}_{14-16}$ & $\mathrm{CC}$ & $\mathrm{X}_{9,12}$ & $\mathrm{CXC}$ & $\mathrm{X}_{24}$ & $\mathrm{C}$ & $X_{7-10}$ & $\mathrm{C}$ \\
\hline $\mathrm{V}$ & 1 & $\mathrm{C}$ & $\mathrm{X}_{14}$ & $\mathrm{C}$ & $\mathrm{X}_{14}$ & $\mathrm{CC}$ & $\mathrm{X}_{11}$ & $\mathrm{CXC}$ & $\mathrm{X}_{24}$ & $\mathrm{C}$ & $\mathrm{X}_{10}$ & $\mathrm{C}$ \\
\hline VII & 5 & $\mathrm{C}$ & $\mathrm{X}_{9}$ & $\mathrm{C}$ & $X_{14,16}$ & $\mathrm{CC}$ & $\mathrm{X}_{12}$ & $\mathrm{CXC}$ & $X_{25,27}$ & $\mathrm{C}$ & $\mathrm{X}_{9}$ & $\mathrm{C}$ \\
\hline VIII & 7 & $\mathrm{C}$ & $\mathrm{X}_{6}$ & $\mathrm{C}$ & $\mathrm{X}_{12,14}$ & $\mathrm{CC}$ & $\mathrm{X}_{12}$ & $\mathrm{CXC}$ & $\mathrm{X}_{25,27}$ & $\mathrm{C}$ & $\mathrm{X}_{8}$ & $\mathrm{C}$ \\
\hline XIII & 6 & $\mathrm{C}$ & $\mathrm{X}_{9}$ & $\mathrm{C}$ & $\mathrm{X}_{14}$ & $\mathrm{CC}$ & $\mathrm{X}_{12}$ & $\mathrm{CXC}$ & $X_{26,30}$ & $\mathrm{C}$ & $\mathrm{X}_{8}$ & $\mathrm{C}$ \\
\hline
\end{tabular}

字符 “ $X$ ” 代表任何种类的氨基酸, “ $X$ ” 后的阿拉伯数字代表氨基酸残基的数量。

The character “ $X$ ” represents any kind of amino acid, and the arabic numeral after the "X" represents the number of amino acid residues.

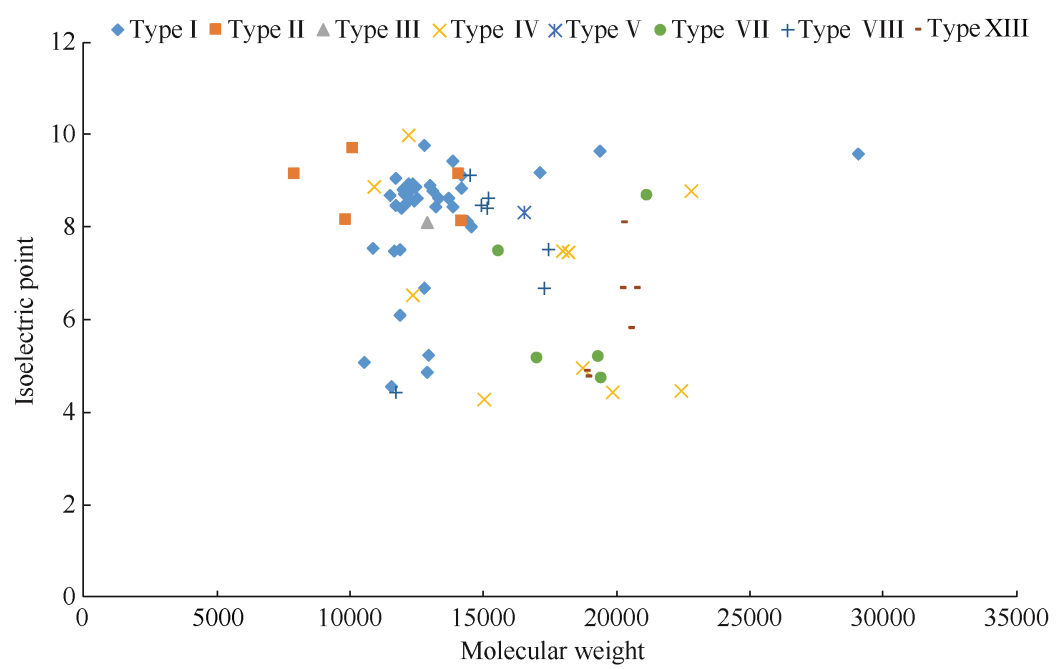

图 1 烟草 nsLTPs 蛋白的分子量和等电点的分布

Fig. 1 Distributions of molecular weights and isoelectric points of tobacco nsLTPs 


\section{3 烟草 nsLTPs 的系统发育分析}

使用 MEGA 6.0 软件, 采用邻接法构建了烟草 nsLTPs 的系统发育树(图 2)。除 IV 型外，其余 7 个 类型的烟草 nsLTPs 分别聚在一起。

\section{4 烟草 nsLTPs 的基因结构和 motif 分析}

通过将烟草 nsLTPs 的基因组 DNA 与 CDS 进行 比较, 分析了烟草 $n s L T P S$ 的内含子-外显子结构(图 $3)$ 。I 型 $n s L T P s$ 的大部分成员含有 1 3 个外显子, 其 中 14 条基因没有内含子, 17 条基因含有 2 个外显子 和 1 个内含子, 6 条基因含有 3 个外显子和 2 个内含 子, 而Nitab4.5_0000102g0410含有 5 个外显子和 4 个内含子。II 型中, 有 3 条基因没有内含子, 2 条基 因含有 1 个内含子, 1 条基因含有 2 个内含子。IV 型
中, 有 3 条基因含有 4 个外显子, 3 条基因含有 3 个 外显子, 3 条基因含有 2 个外显子, 1 条基因不含内含 子。VII 型中大多数含有 3 个外显子, VIII 型大多数 含有 2 个外显子, 在 XIII 型中, 有 3 条基因含有 3 个外显子, 3 条含有 2 个外显子的基因。

每种类型的 NtLTPs 都由相似的保守基序组成, motif 2 和 motif 3 存在于所有类型的 NtLTPs 中。另 外, 有些保守基序仅存在于少数类型中, 例如, motif 4 仅在 I 型存在, motif 9 仅在 VIII 型存在, motif 7 仅在 XIII 型存在。

同时，对每种类型的 ECM 基序进行 seqlogo 分 析(图 4)发现, 每种类型的 nsLTPs 蛋白都具有保守 的 ECM 基序, 即保守的 8 个半胱氨酸残基。

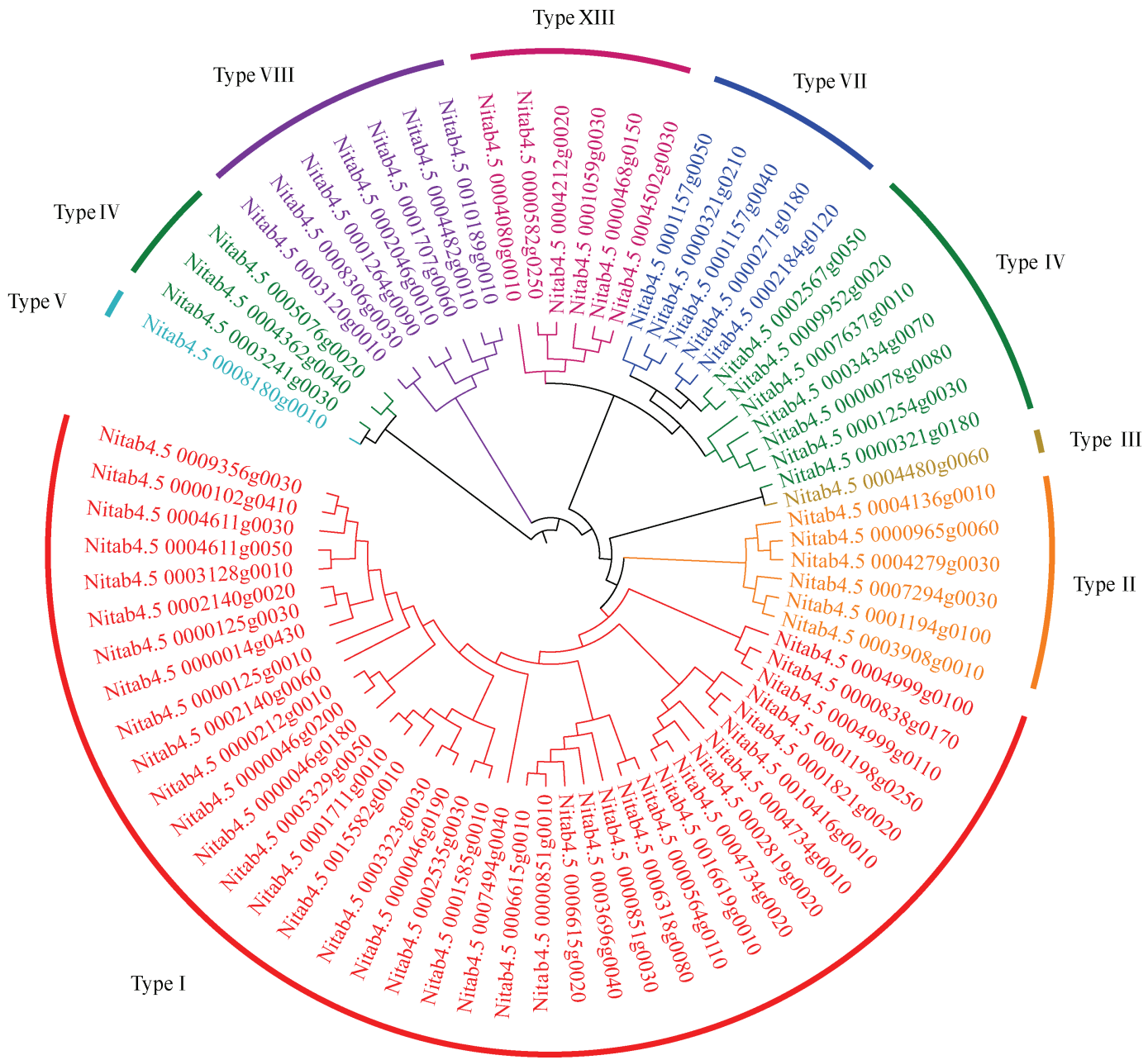

图 2 烟草中 $n s L T P s$ 家族的系统发育关系

Fig. 2 Phylogenetic relationship of $n s L T P s$ family in tobacco 


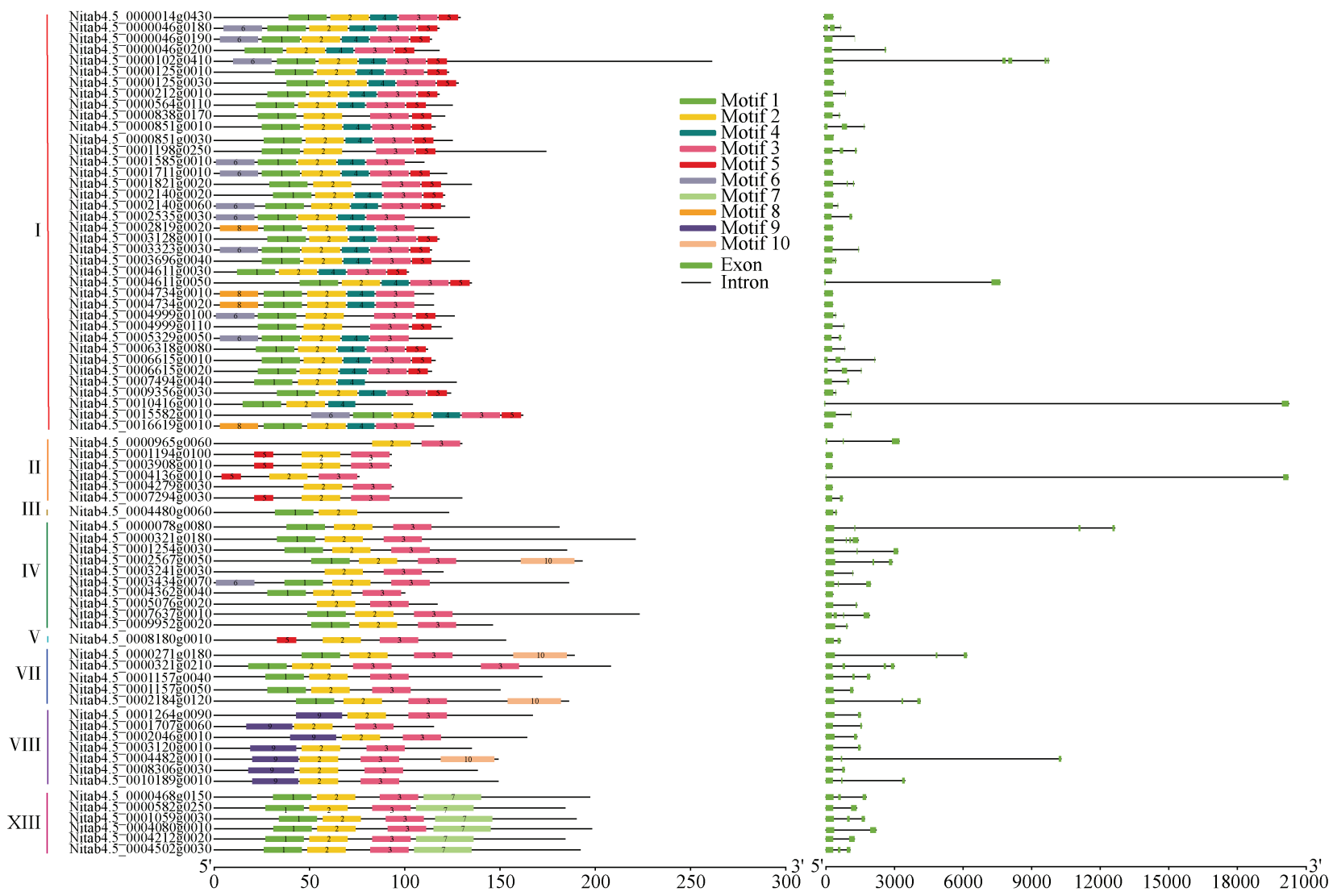

图 3 烟草 nsLTPs 蛋白的保守基序(中间部分)和 nsLTPs 基因的基因结构(右侧部分)

Fig. 3 Conserved motifs of tobacco nsLTPs proteins (middle part) and gene structures of nsLTPs genes (right part) in tobacco

I

II

III $2_{0}^{2.0}$

IV 2.0 .0 .

$\mathrm{V} \stackrel{2.0}{2.0}$

VII

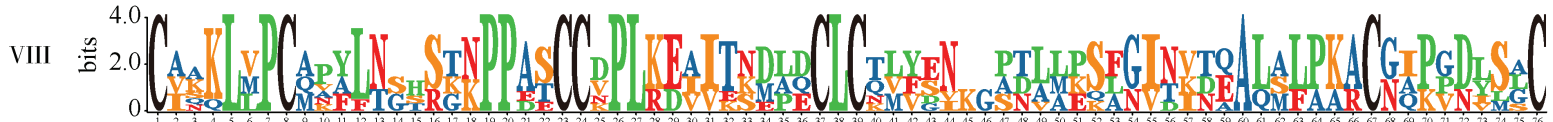

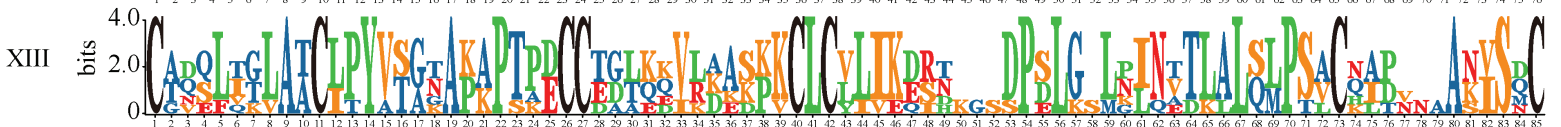

图 4 烟草 nsLTPs 的保守半胱氨酸结构域

Fig. 4 Conserved cysteine domain of nsLTPs in tobacco 
2.5 烟草 nsLTPs 的染色体定位与基因重复性分析 从烟草基因组中下载了烟草品种 $\mathrm{K} 326$ 的染 色体长度、NtLTPs 基因在染色体上的位置等注释 信息, 74 条 NtLTPS 基因序列中有 42 条序列定位在 染色体上，以此，绘制了 42 条基因在染色体上的 分布图(图 5)。结果发现, 17 号染色体上的 NtLTPS 数量最多, 有 7 个; 2 号和 23 号染色体上分别有 5 个。在 $3 、 5 、 6 、 12 、 15 、 18 、 21$ 和 24 号染色体 上, 分别只有 1 个基因, 其余 6 个染色体上不含 NtLTPs 家族基因。

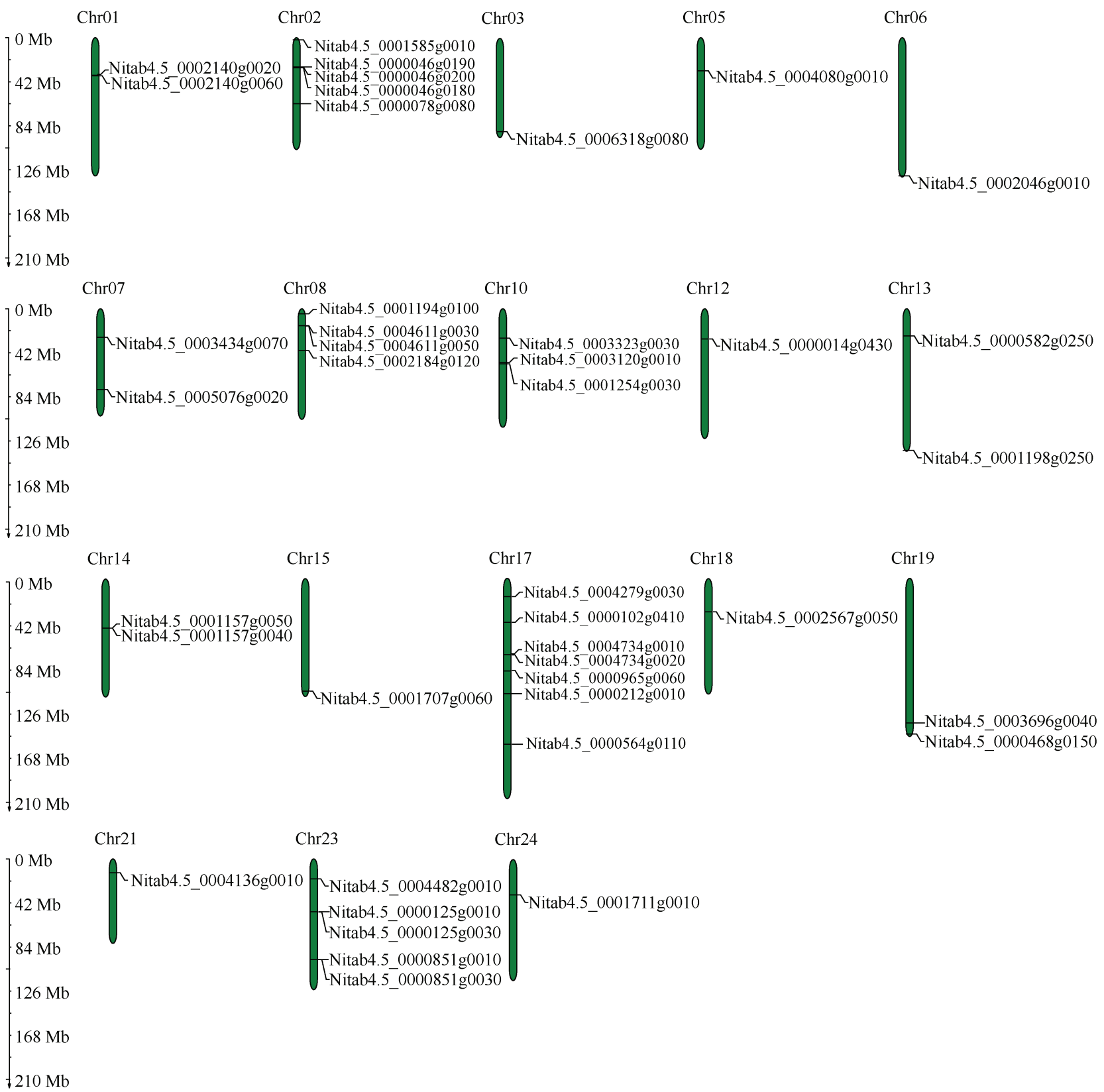

对 42 条可以定位到染色体上的 NtLTPs 序列 进行了序列一致性分析，将序列同一性 $\geq 70 \%$ 视 为 1 个基因对。共找到了 7 个基因对，其中有 6 个基因对属于 I 型，另外 1 对属于IV型。基因重复 事件分为串联重复和片段重复, 基因重复事件导 致了物种进化过程中基因家族的扩增 ${ }^{[33]}$ 。按同一条 染色体上的 $100 \mathrm{~kb}$ 染色体片段中，2 个基因之间的 间隔少于 5 个基因的标准, 判断是否为串联重复基 因 $^{[34]}$ 。结果发现，7 个基因对中有 1 个串联重复基 因对，6 个片段重复基因对，对其进行了可视化分 
析(图 6), 串联重复发生在 17 号染色体上。本研究 中, 串联重复和片段重复事件均促进了烟草中 nsLTPs 家族的扩展, 而片段重复对于扩大烟草 nsLTPs 基因家族更为重要。

此外, 计算了重复基因对之间的 $\mathrm{Ka} / \mathrm{Ks}$ 值以评 估烟草 $n S L T P s$ 的分子进化速率, $\mathrm{Ka} / \mathrm{Ks}$ 的比值可用
作选择压力的标志(图 7)。 $\mathrm{Ka} / \mathrm{Ks}$ 的比值大于 1 表示 正选择, 小于 1 表示纯化选择, 等于 1 则表示中性选 择 $^{[35]}$ 。结果发现, $\mathrm{Ka}$ 值在 0.01 到 0.20 之间, $\mathrm{Ka} / \mathrm{Ks}$ 值均小于 1, 这表明来自烟草品种 K326 的所有重 复 $n s L T P s$ 基因都是由重复事件后的纯化选择压力 驱动的。

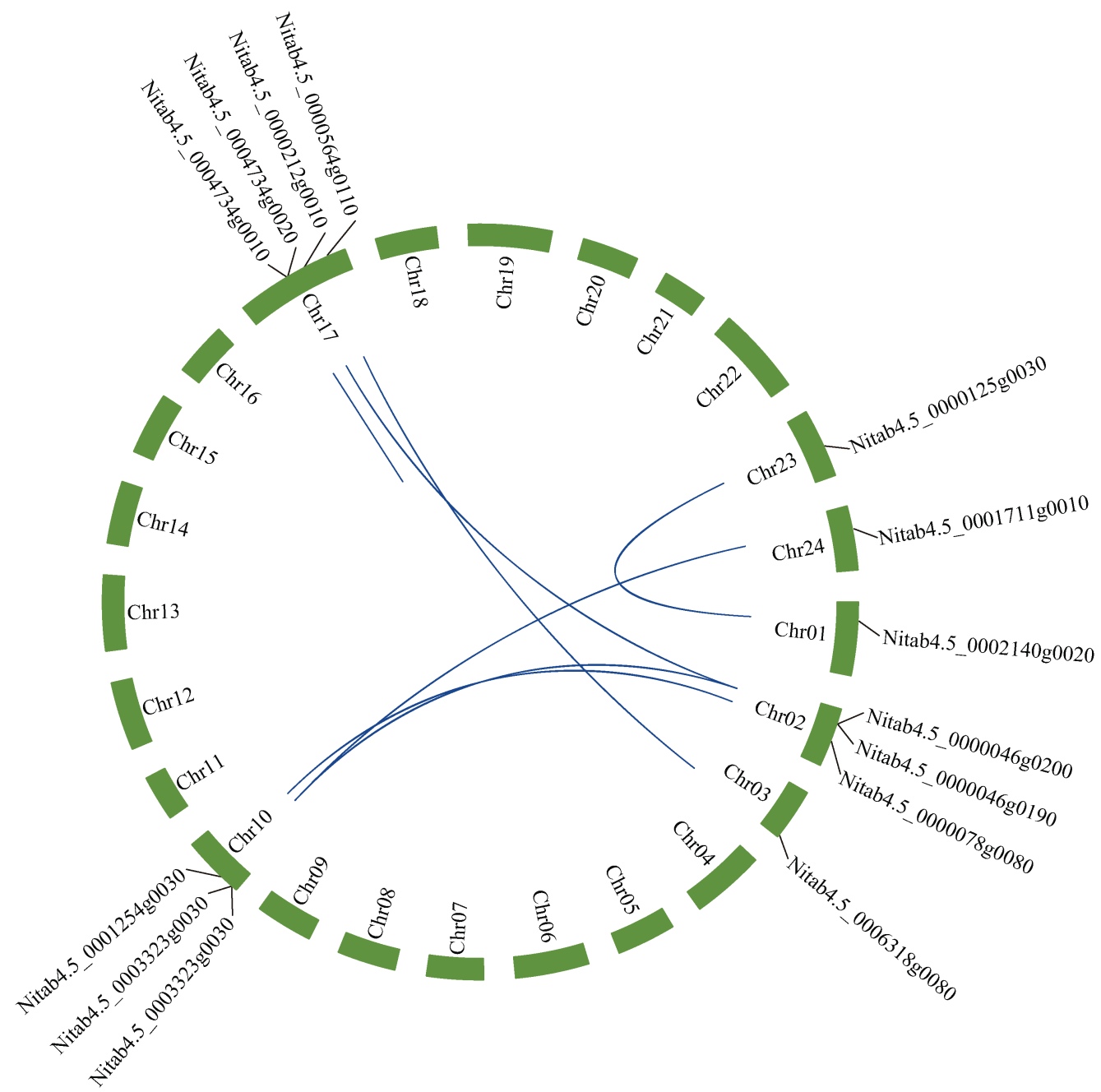

图 6 烟草中 $n s L T P S$ 基因的基因重复

Fig. 6 Gene duplications of nsLTPs genes in tobacco
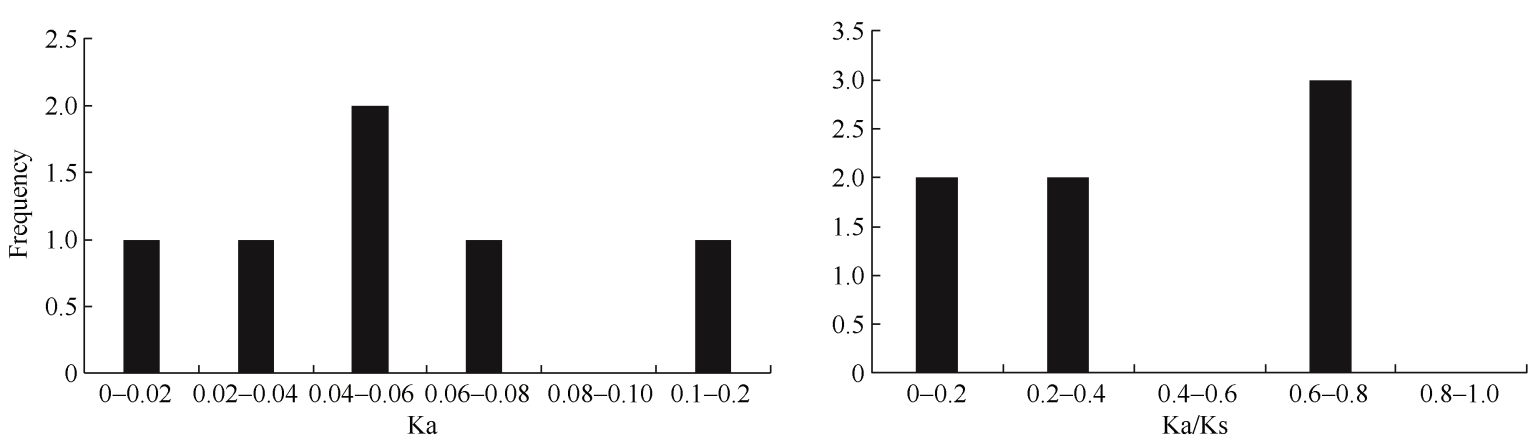

图 7 重复的 NtLTPs 基因之间的 $\mathrm{Ka}$ 和 $\mathrm{Ka} / \mathrm{Ks}$ 值的频率分布

Fig. 7 Frequency distribution of $\mathrm{Ka}$ and $\mathrm{Ka} / \mathrm{Ks}$ values of duplicated $N t L T P s$ gene pairs 


\section{6 烟草 nsLTPs 的 3D 结构预测}

选取 8 种类型中的 9 条 nsLTPs 蛋白序列为代表 预测了其蛋白 3D 结构, 其中, I 型 NtLTPs 的数量较
多, 选择了 2 条。由图 8 可知, 烟草 nsLTPs 蛋白的 3D 结构具有 nsLTPs 蛋白的典型特征, 即 4 个 $\alpha$-螺 旋以及在内部形成的一个疏水空腔。

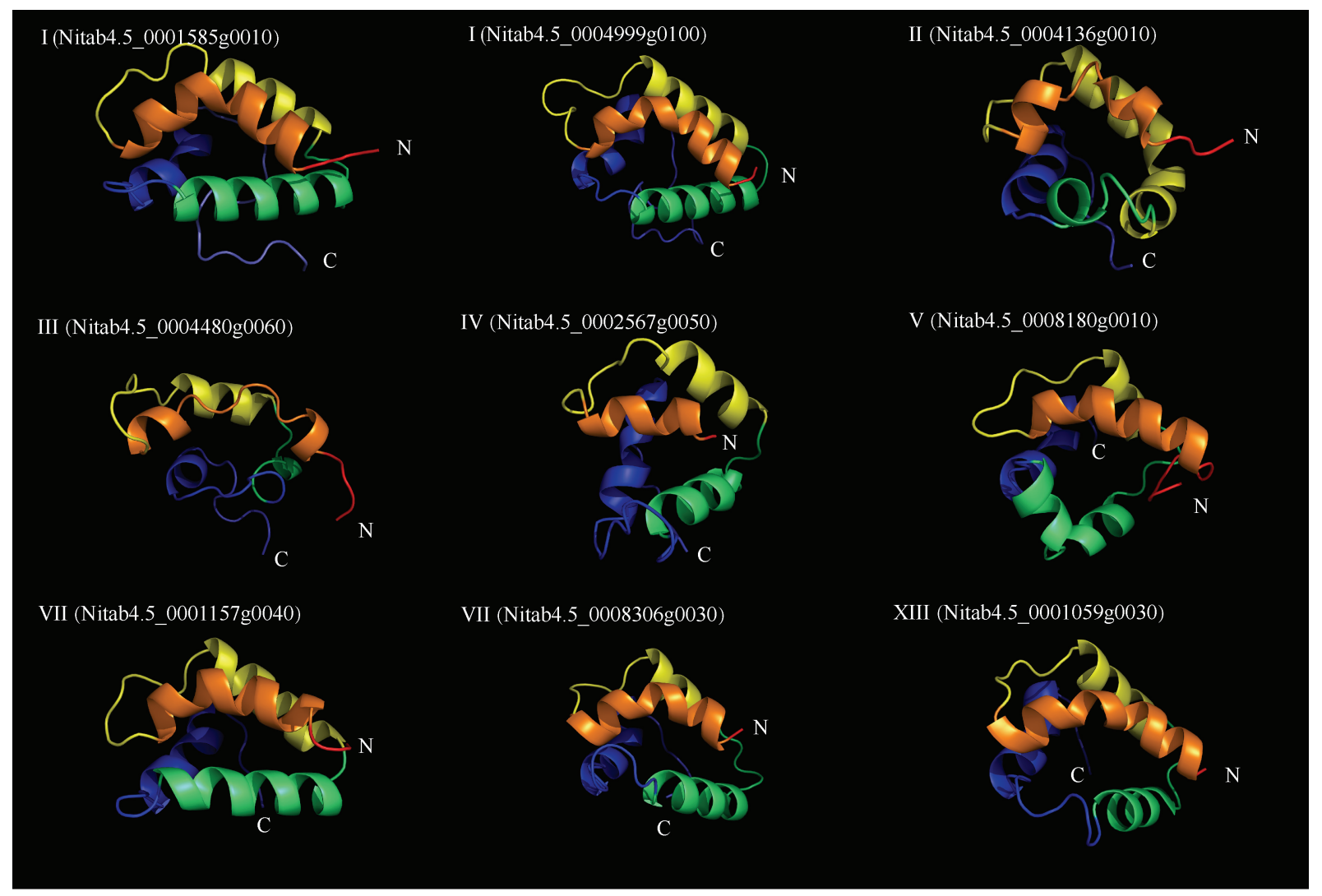

图 8 烟草中 9 个 nsLTPs 蛋白的 3D 结构

Fig. 8 3D-structure of nine nsLTPs proteins in tobacco

\section{7 烟草 nsLTPS 的顺式作用元件分析}

启动子中的顺式作用元件可以作为转录因子的 结合位点, 并参与基因表达的调控。顺式作用元件 分布的规律可能揭示了功能和调控水平的差异。使 用 PlantCARE 在线网站预测分析了 74 个烟草 nsLTPs 基因的转录起始位点 $2000 \mathrm{bp}$ 的上游区域。由图 9 可 知, 一共篮选了 21 种顺式作用元件。这些元件可以 分为 3 种类型。第 1 类与植物激素有关, 包括 ABRE、 AuxRR-core、CGTCA-motif、GARE-motif、P-box、 TCA-element、TGACG-motif 和 TGA-element。第 2 种类型与非生物胁迫有关，包括 TC-rich repeats、

TATC-box、ARE、GC-motif、LTR、MBS、X3.AF1. binding site 和 MBSI。第 3 类是光响应有关的元件, 包括 ACE、G-box、MRE、Sp1 和 GT1-motif。不同 烟草 nsLTPs 的启动子中相关元件的分布规律不同, 表明它们可能执行不同的功能。其中，与光响应有 关的元件如 G-box 元件、抗氧化反应元件 ARE 和
$\mathrm{ABA}$ 响应元件 ABRE, 在大多数 NtLTPs 家族基因启 动子中存在, 表明它们可能在调节 NtLTPs 的功能方 面起到重要作用。

2.8 干旱处理下的转录组差异基因表达分析 对于从 NCBI SRA 数据库获得的烟草品种 K326 苗期干旱处理的转录组数据, 从中篮选 nsLTPs 基因 家族数据, 使用 FPKM 算法计算了 $n s L T P s$ 基因的表 达量, 以 FDR 小于 0.05 且表达差异大于 2 为差异标 准, 有 30 个 nsLTPs 基因在干旱处理后显现显著性 基因表达差异, $\log _{2}$ 标准化后绘制差异基因表达量热 图(图 10), 结果发现, 在干旱处理下, 14 个 nsLTPs 基因表达量显著性上调，包含 9 个 I 型, 2 个 II 型, IV、 VIII 和 XIII 型各 1 个; 16 个 nsLTPs 基因表达量显著 性下调, 包含 4 个 I 型, 7 个 IV 型, 2 个 VII 型、1 个 VIII 型和 2 个 XIII 型; 表明不同的 nsLTPs 家族基因 在干旱处理下显示出不同的表达模式, 虽然表达模 式和类型之间没有特定的对应关系, 但 I 型和 IV 型在 
干旱处理后显著性上调和下调的基因数目最多。

\section{9 烟草 nsLTPs 基因的表达模式分析}

使用 qRT-PCR 分析了 Nitab4.5_0000125g0010 (I

型)和 Nitab4.5_0004362g0040 (IV 型)基因在根、茎、

下部叶、中部叶、上部叶和花中的表达模式。
由图 11 可知, I 型 Nitab4.5_0000125g0010 基因在烟 草品种 K326 中部叶表达水平最高, 而 IV 型 Nitab4.5_0004362g0040 基因在茎中表达水平最高, 表明 NtLTPs 基因的表达具有组织特异性, 不同基因 组织间的表达模式也存在差异。

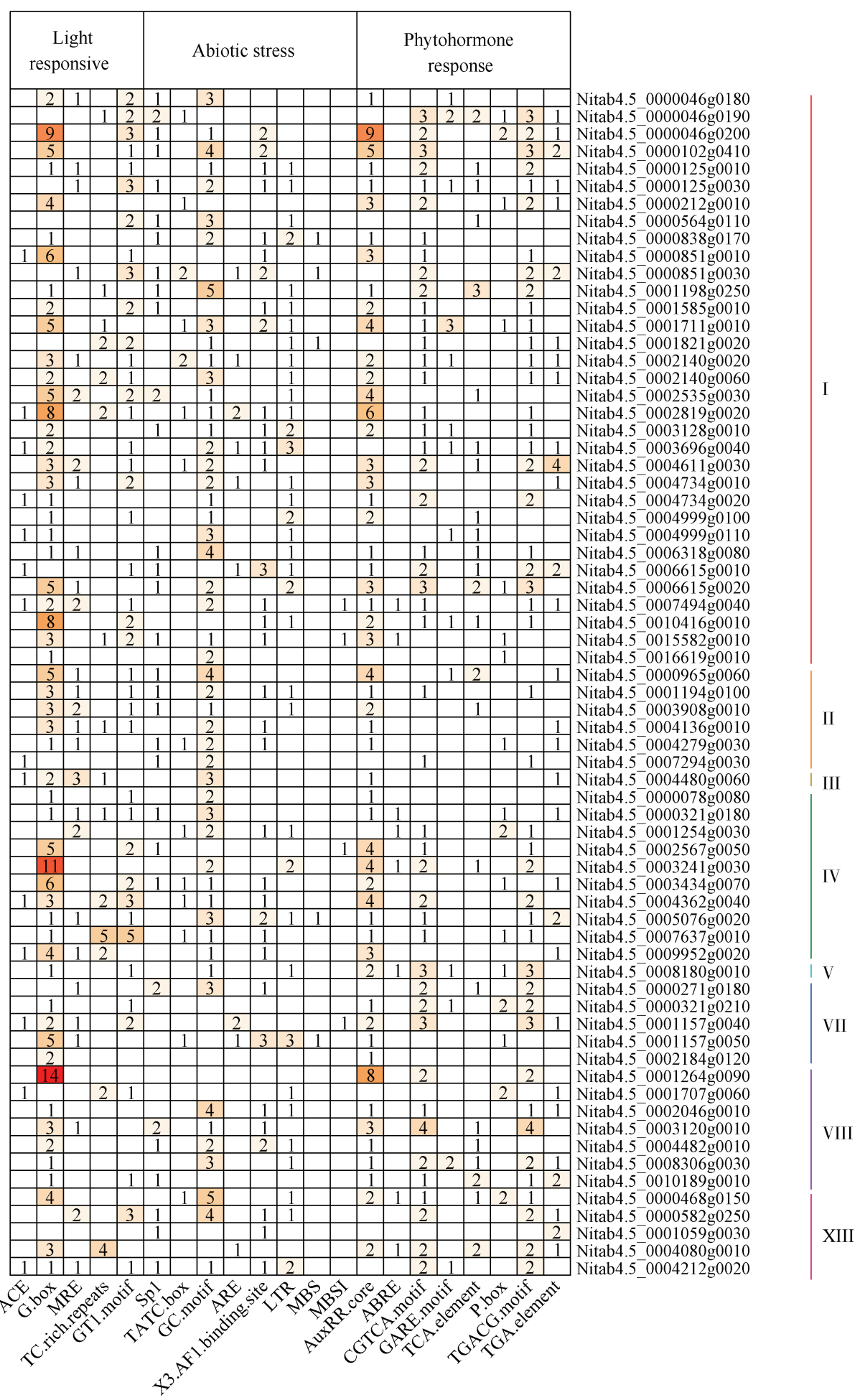

图 9 烟草 nsLTPS 启动子的顺式作用元件分析

Fig. 9 Cis-acting elements of nsLTPs promoter in tobacco 

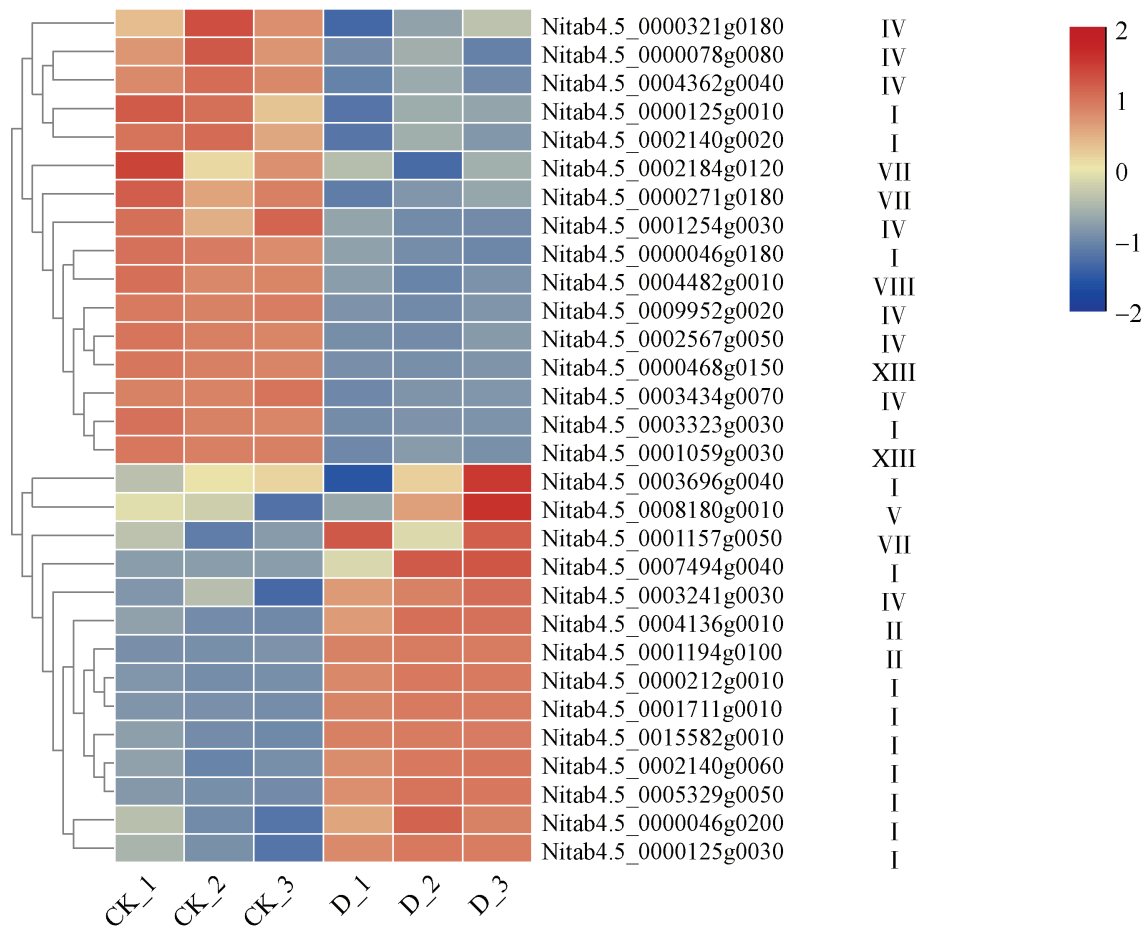

图 10 干旱处理下烟草品种 $\mathrm{K} 326$ 的差异基因热图

Fig. 10 Relative expression profile of variety K326 under drought treatment in tobacco

使用每个样本的 FPKM 数值 $\log _{2}$ 标准化后绘制差异基因表达量热图。CK 表示未进行干旱处理, D 表示干旱处理, 均包含 3 个重复。 红色和蓝色分别表示表达量高和低。

The relative expression levels of $n s L T P s$ are measured by FPKM value in RNA-seq data and the relative expression heatmap are drew after FPKM normalized by $\log _{2}$. CK represents no drought treatment, and D represents drought treatment. Red and white color indicate high and low expression levels, respectively.

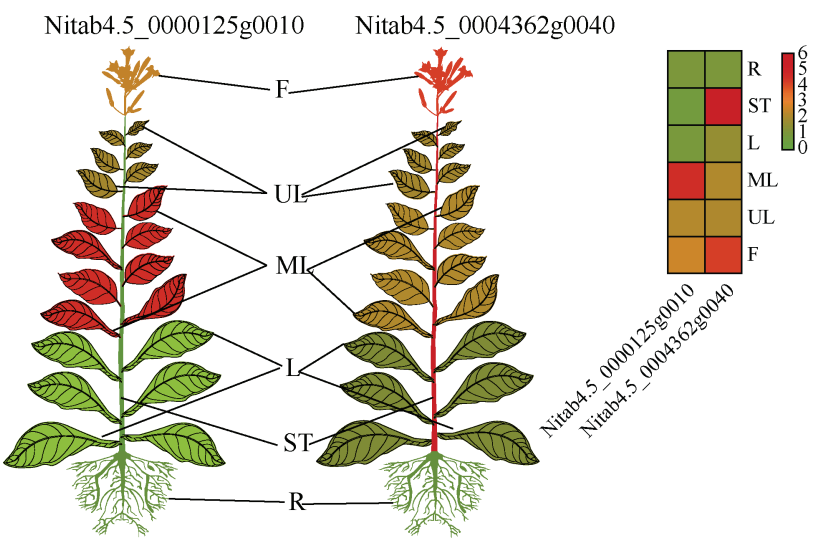

图 11 Nitab4.5_0000125g0010 (I 型)和 Nitab4.5_0004362g0040 基因(IV 型)在烟草不同组织中的表达水平

Fig. 11 Relative expression levels of Nitab4.5_0000125g0010 (type I) and Nitab4.5_0004362g0040 (type IV) in different tissues of tobacco

以根中的相对表达量作为对照, 红色和绿色表示相对表达量高和低。R: 根; ST: 茎; L: 下部叶; ML: 中部叶; UL: 上部叶; F: 花。

The relative expression levels in the roots were used as controls, with high and low relative expression levels in red and green, respectively. R: root; ST: stem; L: lugs; ML: middle leaf; UL: upper leaf; F: flower.

使用 qRT-PCR 分析了非生物胁迫(干旱、盐和 高温)和激素胁迫(ABA、SA、MeJA、IAA 和 GA) 处理下 Nitab4.5_0000125g0010 (I 型)和 Nitab4.5 $0004362 g 0040$ (IV 型)的表达模式(图 12)。结果表 明, NtLTPs 家族基因可以响应多种激素和非生物胁
迫，不同类型的基因在相同的胁迫下表现出相似 或不同的表达模式，例如，在 $37^{\circ} \mathrm{C} 、 \mathrm{NaCl}$ 和 IAA 处理下，2 个基因的表达模式相似; 而在甘露醇 (Mannitol)和 ABA 处理后, Nitab4.5_0000125g0010 基因的表达在 $6 \mathrm{~h}$ 或 $9 \mathrm{~h}$ 达到高峰, 随后降低, 

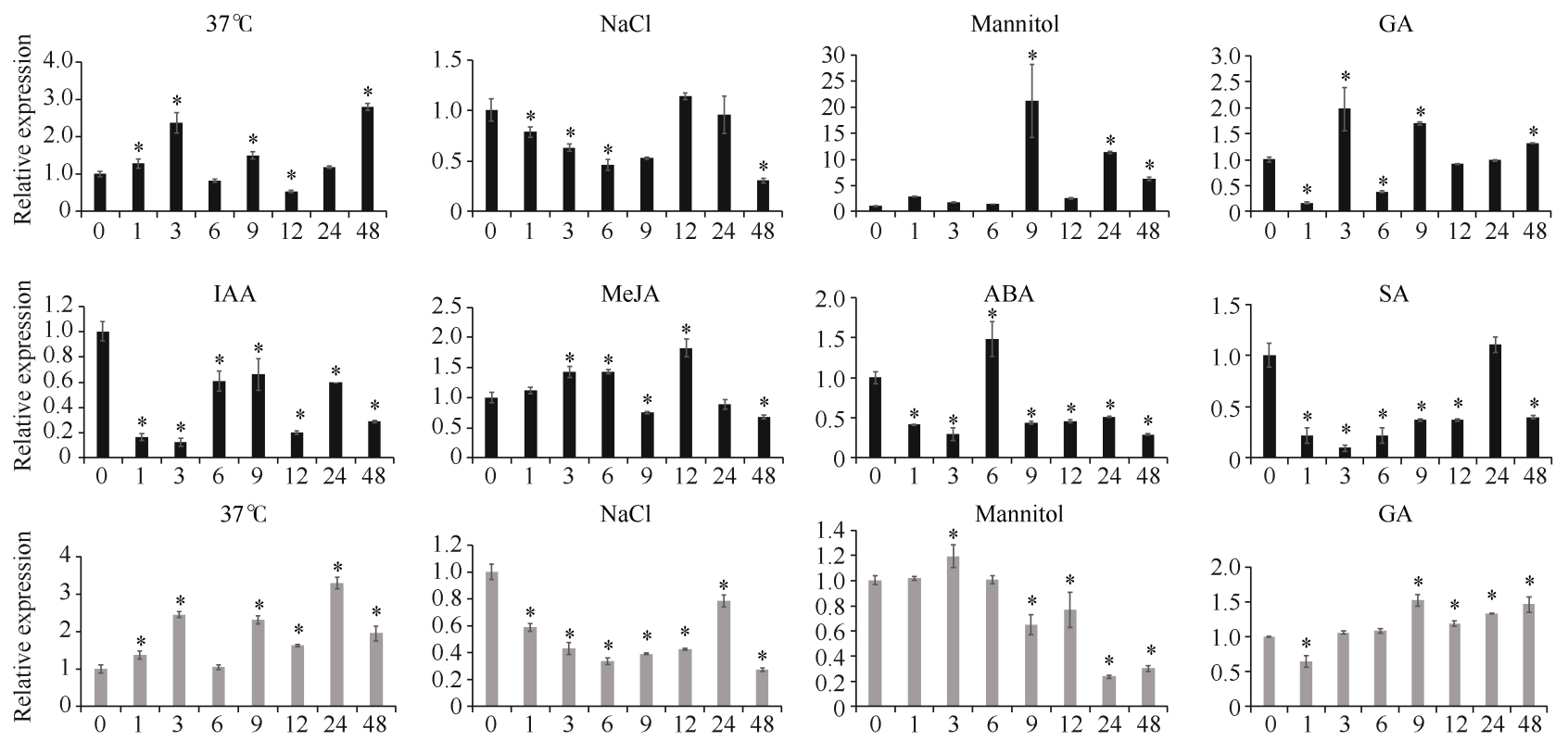

IAA
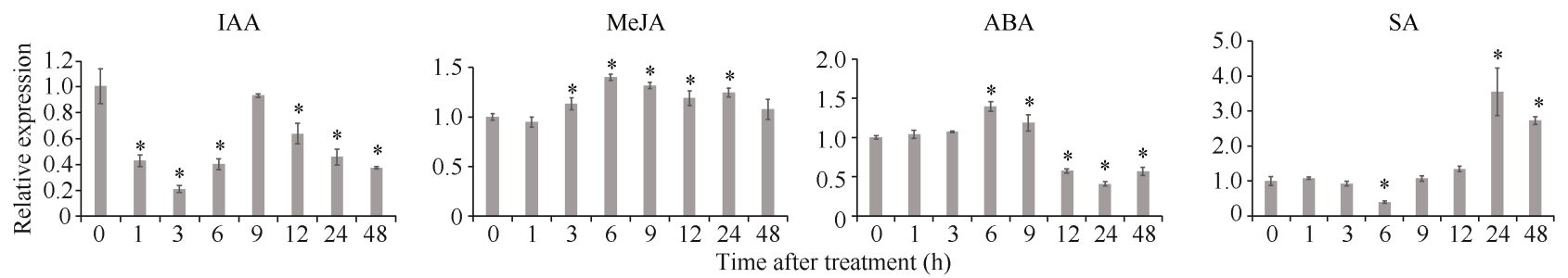

图 12 Nitab4.5_0000125g0010 (黑色)和 Nitab4.5_0004362g0040 基因(灰色)在不同处理下的表达模式

Fig. 12 Relative expression patterns of Nitab4.5_0000125g0010 (black) and Nitab4.5_0004362g0040 (gray) under different treatments

用 $2^{-\Delta \Delta \mathrm{CT}}$ 方法计算相对基因表达量。将 $0 \mathrm{~h}$ 的相对表达量设置为 1 。误差线表示 3 个生物学重复的标准偏差。 $37^{\circ} \mathrm{C}$ : 高温处理; $\mathrm{NaCl}$ : 盐 处理; Mannitol: 甘露醇处理; GA: 赤霉素处理; IAA: 生长素处理; MeJA: 茉莉酸甲酯处理; ABA: 脱落酸处理; SA: 水杨酸处理。*表 示在 0.05 水平上差异显著。

The relative gene expression was calculated by $2^{-\Delta \Delta C T}$ method. The relative expression of $0 \mathrm{~h}$ was set to 1 . Error bars represent the standard deviations of three biological replicates. $37^{\circ} \mathrm{C}$ : high temperature treatment; $\mathrm{NaCl}$ : salt treatment; Mannitol: mannitol treatment; $\mathrm{GA}$ : gibberellin treatment; IAA: auxin treatment; MeJA: methyl jasmonate treatment; ABA: abscisic acid treatment; SA: salicylic acid treatment. *: $P<0.05$.

Nitab4.5_0004362g0040基因的表达只是略微升高, 随后下降。

\section{3 讨论}

NsLTPs 在植物界中广泛存在, 8 个 Cys 通过 4 个二硫键连接形成 4 个 $\alpha$-螺旋并在内部形成一个疏 水腔 ${ }^{[36]}$, 是结合和转移脂质的植物蛋白中功能最重 要的一类。本研究鉴定的 nsLTPs 序列中, 我们删除 了含有不完整的 ECM 基序的序列。以往的研究中, 由 Boutrot 等 ${ }^{[5]}$ 和 Edstam 等 ${ }^{[9]}$ 鉴定的 nsLTPs 序列包 含不完整的 ECM 基序, Wang 等 ${ }^{[25]}$ 在黄瓜中鉴定出 的 39 个 nsLTPs 都只含有 5 个 Cys, Cys1、Cys2 和 Cys8 缺失, 这与典型的 nsLTPs 不同。Wei 等 ${ }^{[11]}$ 排除 了包含不完整 ECM 基序的序列, 认为包含不完整的 $8 \mathrm{CM}$ 结构不能被认为是 nsLTPs。据报道，保守的 8
个半胱氨酸基序中 2 个二硫键丢失可能导致水稻在 长日和低温条件下严重矮化 ${ }^{[37]}$ 。目前, 还没有确定 用于划分 nsLTPs 的统一标准, 不同的篮选方法可能 导致结果的不同, 而且, Cys 缺失的序列是否与包含 完整 $8 \mathrm{CM}$ 结构的 nsLTPs 序列具有相似的功能, 是 否会发生功能的改变, 还需要进一步的研究。

在本研究中, 我们从烟草品种 K326 基因组中 鉴定出 74 个 nsLTPs 基因, 基于 Boutrot 等 $^{[5]}$ 的分类 方法, 我们无法对所有的烟草 nsLTPs 进行分类。因 此，在 Boutrot 等分类方法的基础上, 结合系统发 育关系，基因结构以及保守 motif 的比较，最终将 其划分为 8 种类型 (I、II、III、IV、V、VII、VIII 和 XIII), 没有 VI 型和 IX 型。在 Boutrot 等的分类 方法中, 所有的 VI 型在 Cys7 之前的第 4 位为 Val, Cys 7 之前的第 10 位为 Met, 并以此来和 IV 型区分, 
但是在我们鉴定的烟草 nsLTPs 中没有发现满足上 述条件的序列。此外，在 I 型中 CC 和 CXC 之间氨 基酸残基的数量也有不同，在本研究的分类中除 19 之外还有 20 和 22 , 这种现象也出现在棉花中(除 19 之外还含有 20$)^{[38]}$ 。XIII 型为一个新型, 首次在 同为茄科的马铃薯中出现，我们的序列中有 7 条序 列符合此分类特征，在它们第 6 个和第 7 个 Cys 之 间有 26 或 30 个氨基酸残基，以此，本研究把它们 归为 XIII 型 ${ }^{[8]}$ 。

内含子-外显子结构模式携带有基因家族进化 的烙印 ${ }^{[34]}$ 。植物在进化过程中倾向于保留较少内含 子或短内含子的基因 ${ }^{[40]}$ 。本研究中, 大多数 $N t L T P S$ 基因含有 1 3 个内含子或没有内含子, 这与先前的 研究结果一致 ${ }^{[7,41]}$ 。物种在进化过程中, 已知大多数 被子植物会经历整个基因组的一次或多次重复。水 稻、小麦和拟南芥的多种 nsLTPs 亚型的系统进化分 析表明，基因和染色体片段的重复目前仍在继续。

进化中, 重复的 $n s L T P s$ 基因突变可能导致基因假基 因化，亚功能化(保留祖先基因的某些功能)或新功 能化(即该基因获得全新功能)，从而会出现具有不 同生物活性及结构和功能上与 nsLTPs 已有类型成员 明显不同的蛋白 ${ }^{[42]}$ 。本研究中, 片段重复对烟草 NtLTPs 基因家族的扩张更为重要。

干旱处理后的 RNA-seq 数据分析显示, 30 个 nsLTPs 基因在干旱处理后显著上调或者下调表达, 说明 nsLTPs 家族在干旱调控方面具有重要作用。 其中 I 型和 IV 型在干旱处理后显著性上调和下调的 基因数目最多, 分别为 9 个和 4 个。对 NtLTPs 家 族的基因重复分析结果也显示该家族的重复事件 主要发生在 I 型和IV型间。但不同的重复基因对在 干旱处理后呈现不同的表达模式，比如重复基因对 中的 Nitab4.5_0003323g0030 (I 型)干旱处理后表达 量显著下调, 但 Nitab4.5_0000046g0190 (I 型)却检 测不到表达量; 重复基因对 Nitab4.5 $0002140 g 0020$ (I 型)和 Nitab4.5_0000125g0030 (I 型) 以及重复基因对 Nitab4.5_0003323g0030 (I 型)和 Nitab4.5_0001711g0010 (I 型)在干旱处理后则分别 都呈现下调和上调的完全相反的趋势; 重复基因对 Nitab4.5_0000212g0010 (I 型 ) 和 Nitab4.5 $0000046 g 0200$ (I 型)在干旱处理后均上调, 重复基 因对 Nitab4.5_0001254g0030 (IV 型)和 Nitab4.5 $0000078 \mathrm{~g} 0080$ (IV 型)在干旱处理后均下调, 这表 明不同基因在进化过程中重复事件发生后功能分 化模式存在差异。
基因的表达受到启动子中顺式作用元件的调控, 启动子区域中顺式作用元件的数量和类型对于各种 胁迫下的基因表达非常重要。NtLTPs 基因家族的启 动子中含有多个响应光照、高温、低温、干旱以及 激素信号如脱落酸、茉莉酸甲酯、生长素、赤霉素 等的顺式作用元件, 但不同基因含有的数量及类型 存在差异, 说明不同类型的 NtLTPs 家族基因功能上 可能存在分化。采用 qRT-PCR 分析 NtLTPs 在非生 物胁迫和激素胁迫下的表达模式发现, NtLTPs 家族 基因可以响应多种激素和非生物胁迫, 不同类型的 基因在不同胁迫下具有相似或者不同的表达模式, 暗示了功能上可能存在差异。其中, Nitab4.5 $0000125 g 0010$ 和 Nitab4.5_0004362g0040 基因在干 旱处理下的 RNA-seq 结果都显著下调, 与甘露醇处 理之后 2 个基因的表达模式基本一致(图 11), 虽然 在甘露醇处理之后有短暂的上升, 但随后呈现出下 降的趋势。总之, 本研究对 NtLTPs 基因家族的分析 对于将来进一步针对特定的基因研究其具体的功能 提供了一定的依据。

\section{4 结论}

本研究首次从烟草品种 K326 中鉴定出 74 个 nsLTPs 家族基因，根据 8 个半胱氨酸之间的间隔和 序列相似性将其划分为 8 种类型: I、II、III、IV、 V、VII、VIII 和 XIII 型, 并对其进行了系统发育分 析、内含子/外显子基因结构、保守 motif 和染色体 定位分析, 相同类型的 $n s L T P s$ 基因的内含子/外显 子结构、保守 motif 和 3D 结构相似。基因重复和 进化分析显示, 片段重复在 nsLTPs 家族的扩张中 更为重要。对干旱处理下的 RNA-seq 数据进行分析 表明，不同的 nsLTPs 家族基因在干旱处理下具有 不同的表达模式，I 型和IV 型基因显著性上调和下 调的基因数目最多, 重复基因对的功能分化模式多 样。NSLTPS 基因启动子含有多种与光响应、激素 和非生物胁迫相关的顺式作用元件, 采用 qRT-PCR 验证了不同激素(ABA、SA、MeJA、IAA 和 GA) 和非生物胁迫(干旱、盐和高温)处理下 Nitab4.5 $0000125 \mathrm{~g} 0010$ 和 Nitab4.5_0004362g0040 基因的表 达模式, 结果表明, 他们对不同激素和非生物胁迫 均有响应, 但在相同的胁迫下表现出相似或不同的 表达模式。本研究对 NtLTPs 家族基因进行了较为 全面的系统性分析, 研究结果为深入分析 NtLTPs 家族基因的功能提供了理论参考。 


\section{References}

[1] Carvalho A O, Gomes V M. Role of plant lipid transfer proteins in plant cell physiology-a concise review. Peptides, 2007, 28: 1144-1153.

[2] Liu F, Zhang X, Lu C, Zeng X, Li Y, Fu D, Wu G. Non-specific lipid transfer proteins in plants: presenting new advances and an integrated functional analysis. $J$ Exp Bot, 2015, 66: 5663-5681.

[3] Jose-Estanyol M, Gomis-Ruth F X, Puigdomenech P. The eight-cysteine motif, a versatile structure in plant proteins. Plant Physiol Biochem, 2004, 42: 355-365.

[4] Kader J C. Lipid-transfer proteins in plants. Annu Rev Plant Biol, 1996, 47: 627-654.

[5] Boutrot F, Chantret N, Gautier M F. Genome-wide analysis of the rice and Arabidopsis non-specific lipid transfer protein (nsLtp) gene families and identification of wheat nsLtp genes by EST data mining. BMC Genomics, 2008, 9: 86-108.

[6] Liu W, Huang D, Liu K, Hu S, Yu J, Gao G, Song S. Discovery, Identification and comparative analysis of non-specific lipid transfer protein (nsLtp) family in Solanaceae. Genom Proteom Bioinf, 2010, 8: 229-237.

[7] D'Agostino N, Buonanno M, Ayoub J, Barone A, Monti S M, Rigano M M. Identification of non-specific lipid transfer protein gene family members in Solanum lycopersicum and insights into the features of Sola 13 protein. Sci Rep (UK), 2019, 9: 1607.

[8] Li G, Hou M, Liu Y, Pei Y, Ye M, Zhou Y, Huang C, Zhao Y, Ma H. Genome-wide identification, characterization and expression analysis of the non-specific lipid transfer proteins in potato. $B M C$ Genomics, 2019, 20: 375.

[9] Edstam M M, Viitanen L, Salminen T A, Edqvist J. Evolutionary history of the non-specific lipid transfer proteins. Mol Plant, 2011, 4: 947-964.

[10] Fang Z W, He Y Q, Liu Y K, Jiang W Q, Song J H, Wang S P, Ma D F, Yin J L. Bioinformatic identification and analyses of the non-specific lipid transfer proteins in wheat. J Integr Agric, 2019, 18: $2-17$

[11] Wei K F, Zhong X J. Non-specific lipid transfer proteins in maize. BMC Plant Biol, 2014, 14: 281.

[12] Zhang M Y, Kim Y J, Zong J, Lin H, Dievart A, Li H J, Zhang D B, Liang W Q. Genome-wide analysis of the barley non-specific lipid transfer protein gene family. Crop J, 2019, 7: 65-76.

[13] Chae K, Gonong B J, Kim S C, Kieslich C A, Morikis D, Balasubramanian S, Lord E M. A multifaceted study of stigma/style cysteine-rich adhesin (SCA)-like Arabidopsis lipid transfer proteins (LTPs) suggests diversified roles for these LTPs in plant growth and reproduction. $J$ Exp Bot, 2010, 61: 4277-4290.

[14] Maldonado A M, Doerner P, Dixon R A, Lamb C J, Cameron R K. A putative lipid transfer protein involved in systemic resistance signalling in Arabidopsis. Nature, 2002, 419: 399-403.

[15] Yeats T H, Rose J K. The biochemistry and biology of extracellular plant lipid-transfer proteins (LTPs). Protein Sci, 2008, 17: 191-198.

[16] Wang H, Sun Y, Chang J, Zheng F, Pei H, Yi Y, Chang C, Dong C H. Regulatory function of Arabidopsis lipid transfer protein 1 (LTP1) in ethylene response and signaling. Plant Mol Biol, 2016,
91: 471-484.

[17] Zaidi M A, O'Leary S J B, Gagnon C, Chabot D, Wu S, Hubbard K, Tran F, Sprott D, Hassan D, Vucurevich T. A triticale tapetal non-specific lipid transfer protein (nsLTP) is translocated to the pollen cell wall. Plant Cell Rep, 2020, 39: 1185-1197.

[18] Deng T, Yao H, Wang J, Wang J, Xue H, Zuo K. GhLTPG1, a cotton GPI-anchored lipid transfer protein, regulates the transport of phosphatidylinositol monophosphates and cotton fiber elongation. Sci Rep (UK), 2016, 6: 26829.

[19] Potocka I, Baldwin T C, Kurczynska E U. Distribution of lipid transfer protein 1 (LTP1) epitopes associated with morphogenic events during somatic embryogenesis of Arabidopsis thaliana. Plant Cell Rep, 2012, 31: 2031-2045.

[20] Finkina E I, Melnikova D N, Bogdanov I V, Ovchinnikova T V. Lipid transfer proteins as components of the plant innate immune system: structure, functions, and applications. Acta Nat, 2016, 8: 47-61.

[21] Gebhardt C, Vieths S, Gubesch M, Averbeck M, Simon J C, Treudler R. $10 \mathrm{kDa}$ lipid transfer protein: the main allergenic structure in a German patient with anaphylaxis to blueberry. Allergy, 2009, 64: 498-499.

[22] Guo L, Yang H, Zhang X, Yang S. Lipid transfer protein 3 as a target of MYB96 mediates freezing and drought stress in Arabidopsis. J Exp Bot, 2013, 64: 1755-1767.

[23] McLaughlin J E, Bin-Umer M A, Widiez T, Finn D, McCormick $\mathrm{S}$, Tumer N E. A lipid transfer protein increases the glutathione content and enhances Arabidopsis resistance to a trichothecene mycotoxin. PLoS One, 2015, 10: e0130204.

[24] Patkar R N, Chattoo B B. Transgenic indica rice expressing ns-LTP-like protein shows enhanced resistance to both fungal and bacterial pathogens. Mol Breed, 2006, 17: 159-171.

[25] Wang X, Li Q, Cheng C, Zhang K, Lou Q, Li J, Chen J. Genome-wide analysis of a putative lipid transfer protein LTP_2 gene family reveals CsLTP_2 genes involved in response of cucumber against root-knot nematode (Meloidogyne incognita). Genome, 2020, 63: 225-238.

[26] Zhu X, Li Z, Xu H, Zhou M, Du L, Zhang Z. Overexpression of wheat lipid transfer protein gene TaLTP5 increases resistances to Cochliobolus sativus and Fusarium graminearum in transgenic wheat. Funct Integr Genom, 2012, 12: 481-488.

[27] Gaier S, Marsh J, Oberhuber C, Rigby N M, Shewry P R. Purification and structural stability of the peach allergens Pru p 1 and Pru p 3. Mol Nutr Food Res, 2008, 52: S220-229.

[28] Palacin A, Varela J, Quirce S, Pozo V D, Tordesillas L, Barranco P, Fernandez-Nieto M, Sastre J, Diaz-Perales A, Salcedo G. Recombinant lipid transfer protein Tri a 14: a novel heat and proteolytic resistant tool for the diagnosis of baker's asthma. Clin Exp Allergy, 2009, 39: 1267-1276.

[29] Choi Y E, Lim S, Kim H J, Han J Y, Lee M H, Yang Y, Kim J A, Kim Y S. Tobacco NtLTP1, a glandular-specific lipid transfer protein, is required for lipid secretion from glandular trichomes. Plant J, 2012, 70: 480-491.

[30] 徐扬. 非特异性脂转移蛋白 NtLTP4 作为正调控因子参与烟草 对非生物和生物胁迫的响应. 山东农业大学博士学位论文, 山东泰安, 2018.

Xu Y. Non-specific Lipid Transfer Protein NtLTP4 as a Positive 
Regulator Involved in Abiotic and Biotic Stress in Nicotiana tabacum. PhD Dissertation of Shandong Agricultural University, Tai'an, Shandong, China, 2018 (in Chinese with English abstract).

[31] Chen C, Chen H, Zhang Y, Thomas H R, Frank M H, He Y, Xia R. TBtools: an integrative toolkit developed for interactive analyses of big biological data. Mol Plant, 2020, 13: 1194-1202.

[32] Lescot M, Déhais P, Thijs G, Marchal K, Moreau Y, Van de Peer Y, Rouzé P, Rombauts S. PlantCARE, a database of plant cis-acting regulatory elements and a portal to tools for in silico analysis of promoter sequences. Nucleic Acids Res, 2002, 30: 325-327.

[33] Cannon S B, Mitra A, Baumgarten A, Young N D, May G. The roles of segmental and tandem gene duplication in the evolution of large gene families in Arabidopsis thaliana. BMC Plant Biol, 2004, 4: 10.

[34] Wang L, Guo K, Li Y, Tu Y, Hu H, Wang B, Cui X, Peng L. Expression profiling and integrative analysis of the CESA/CSL superfamily in rice. BMC Plant Biol, 2010, 10: 282.

[35] Yang Z, Bielawski J P. Statistical methods for detecting molecular. Trends Ecol Evol, 2000, 15: 496-203.

[36] Douliez J P, Michon T, Elmorjani K, Marion D. Mini review: structure, biological and technological functions of lipid transfer proteins and indolines, the major lipid binding proteins from cereal kernels. J Cereal Sci, 2000, 32: 1-20.

[37] Deng W, Li R, Xu Y, Mao R, Chen S, Chen L, Chen L, Liu Y G, Chen Y. A lipid transfer protein variant with a mutant eight-cysteine motif causes photoperiod-and thermo-sensitive dwarfism in rice. $J$ Exp Bot, 2020, 71: 1294-1305.

[38] Li F, Fan K, Ma F, Yue E, Bibi N, Wang M, Shen H, Hasan M M, Wang X. Genomic identification and comparative expansion analysis of the non-specific lipid transfer protein gene family in Gossypium. Sci Rep (UK), 2016, 6: 38948.

[39] Lynch M. Intron evolution as a population-genetic process. Proc Natl Acad Sci USA, 2002, 99: 6118-6123.

[40] Mattick J S, Gagen M J. The evolution of controlled multitasked gene networks: the role of introns and other noncoding RNAs in the development of complex organisms. Mol Biol Evol, 2001, 18: 1611-1630.

[41] Li J, Gao G, Xu K, Chen B, Yan G, Li F, Qiao J, Zhang T, Wu X. Genome-wide survey and expression analysis of the putative non-specific lipid transfer proteins in Brassica rapa L. PLoS One, 2014, 9: e84556.

[42] Moore R C, Purugganan M D. The evolutionary dynamics of plant duplicate genes. Curr Opin Plant Biol, 2005, 8: 122-128. 